Thorax, 1979, 34, 682-683

\title{
"Coughing water": bronchial hyperreactivity induced by swimming in a chlorinated pool
}

\author{
C P MUSTCHIN AND C A C PICKERING
}

From the Chest Clinic, Wythenshawe Hospital, Manchester, UK

Although pulmonary toxicity resulting from the inhalation of chlorine gas is well known in industrial accidents and warfare (Beach et al. 1969; Hamilton and Hardy, 1974) it may not be appreciated that adverse effects may result from bathing in chlorine-sterilised pools. We describe the sudden onset of reversible airways obstruction in three young swimmers.

They were in a party of 24 children who were training intensively for competitions. During a twohour session in a newly opened pool many developed coughs and sore throats. Half had to leave the water prematurely as a result. The pool was treated by a new method that generates and adds chlorine dioxide to the water. This is claimed to be odourless and nonirritant. In fact the children and their parents described a pungent chlorine-like smell at the time, and it is likely that an abnormally large amount of chlorine dioxide or a related compound had been added to the water.

\section{Subjects}

Three subjects were studied. Subjects 1 and 2 were sisters aged 17 and 15 years. Their father had asthma in childhood and their mother had hay fever. Neither had a history of asthma, but the elder girl had hay fever and the younger mild eczema with perennial rhinitis. On skin prick testing the elder was found to be sensitive to grass pollen and the younger to Dermatophagoides pteronyssinus. Subject 3 was a boy aged 12 with no atopic history but strongly positive prick test reactions to grass pollen and cat fur. During a training session all three were among those who developed cough, soreness in the throat and chest, and difficulty in breathing. The girls recovered considerably in one to two days but the boy was more severely affected and was admitted to hospital with signs of airways obstruction. He responded to treatment with bronchodilators and oxygen.

\section{Methods}

The subjects were studied repeatedly at the times shown in the table. The forced expiratory volume in one second $\left(\mathrm{FEV}_{1}\right)$ and forced vital capacity (FVC) were measured with a dry wedge bellows spirometer (Vitalograph). The response to inhalation of salbutamol aerosol $(200 \mu \mathrm{g})$ was noted. In some studies this was preceded by a histamine challenge test using an aerosol of histamine acid phosphate $(0.1 \%)$ delivered $\omega$ from a Wright nebuliser for 1-2 minutes, the same ir dose being given to each subject on each occasion.

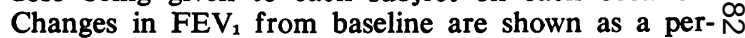
centage in the table. The transfer factor for carbon 을 monoxide (TLCO) was estimated by the single-breath technique.

\section{Results}

The subjects had evidence of airways obstruction that $\vec{\oplus}$ improved over the period of observation. In the girls the $\mathrm{FEV}_{1}$ rose by over one litre in the first week. The boy was studied after a greater degree of recovery had occurred, but both he and the two girls showed an overall pattern of waning bronchoconstriction and re- $\frac{\partial}{0}$ activity to histamine; at one point during the recovery the elder girl had an increased response to histamine, $\mathbb{D}$ coinciding with an attack of hay fever. In the girls the transfer factor was normal when studied. All three $\overrightarrow{0}$ have since recovered completely and returned to their 3 training schedule. Their chest radiographs were normal throughout.

\section{Discussion}

Water is sterilised in most swimming pools by the $\frac{x}{0}$ direct addition of chlorine gas. The pool in question, 3 however, was treated with chlorine dioxide, generated by the addition of hydrochloric acid to sodium hypochlorite in a mixing chamber. Chlorine dioxide is a gas at room temperature, and although correctly $\frac{}{5}$ treated water is described by the equipment manu- $\frac{T}{2}$ facturers as odourless a strong smell was reported by those present at the time of this incident. This is taken $N$ as evidence of an excessive concentration of chlorine or a chlorine compound.

A milder degree of bronchial irritation from low N concentrations of chlorine appears to be common- $\sigma$ place. The children told us that different pools at $<$ times smell unusually strongly of "chlorine," and cause

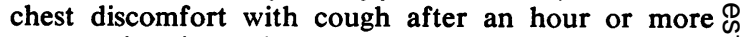
spent swimming. These symptoms usually pass off in ? several hours and may be made briefly worse by taking $T$ a deep breath. They are colloquially known as being $\underset{\mathbb{D}}{\stackrel{O}{D}}$ due to "coughing water." These symptoms typically follow prolonged periods of vigorous swimming, when $\mathbb{D}$ inevitably large volumes of air including gaseous 0 chlorine liberated at the water's surface are inhaled. 
Serial changes in lung function

\begin{tabular}{|c|c|c|c|c|}
\hline Time from onset & & Subject 1 & Subject 2 & Subject 3 \\
\hline 2 days & $\begin{array}{l}\text { FEV }_{1}(\mathrm{l}) \\
\text { FVC }(1) \\
\text { Salbutamol response (\%) } \\
\text { TLCo (mmol/min/kPa)* } \\
\quad \text { Actual } \\
\quad \text { Predicted }\end{array}$ & $\begin{array}{r}1 \cdot 90 \\
4 \cdot 25 \\
+26 \\
\\
11 \cdot 1 \\
9 \cdot 4\end{array}$ & $\begin{array}{r}1 \cdot 60 \\
2 \cdot 40 \\
+15 \\
\\
8 \cdot 0 \\
7 \cdot 7\end{array}$ & $\begin{array}{l}- \\
- \\
-\end{array}$ \\
\hline 6 days & $\begin{array}{l}\mathrm{FEV}_{1}(\mathbf{l}) \\
\text { Histamine reactivity }(\%) \\
\text { Salbutamol response }(\%)\end{array}$ & $\begin{array}{l}3 \cdot 35 \\
-8 \\
0\end{array}$ & $\begin{array}{c}2 \cdot 60 \\
-15 \\
0\end{array}$ & $\overline{-}$ \\
\hline 2 weeks & $\begin{array}{l}\mathrm{FEV}_{1}(\mathrm{l}) \\
\text { Histamine reactivity }(\%) \\
\text { Salbutamol response }(\%)\end{array}$ & 二 & E & $\begin{array}{c}3 \cdot 05 \\
-17 \\
0\end{array}$ \\
\hline 6 weeks & $\begin{array}{l}\mathrm{FEV}_{1}(\mathrm{l}) \\
\text { Histamine reactivity (\%) } \\
\text { Salbutamol response (\%) }\end{array}$ & $\begin{aligned} & 3 \cdot 45 \\
- & 19 \dagger \\
+ & 6\end{aligned}$ & $\begin{aligned} & 2 \cdot 55 \\
- & 6 \\
+ & 6\end{aligned}$ & $\begin{array}{c}3 \cdot 15 \\
-11 \\
0\end{array}$ \\
\hline 6 months & $\begin{array}{l}\text { FEV }_{1}(1) \\
\text { FVC (l) } \\
\text { Histamine reactivity (\%) } \\
\text { Salbutamol response (\%) }\end{array}$ & $\begin{array}{l}3 \cdot 55 \\
4 \cdot 55 \\
-\quad 7 \\
0\end{array}$ & $\begin{array}{l}2 \cdot 50 \\
3 \cdot 30 \\
0 \\
0\end{array}$ & $\begin{array}{l}- \\
- \\
-\end{array}$ \\
\hline
\end{tabular}

FEV $_{1}$, FVC, litres BTPS.

Percentages indicate changes in $\mathrm{FEV}_{1}$.

*SB TLCo-transfer factor; conversion factor, SI to traditional units $=2.99$.

†Concurrent hay fever.

The more severe symptoms seen in these subjects probably represent the effects of excessive quantities of chorine or a derivative.

The atopic state of these children may be relevant to the development of bronchial hyperreactivity and asthmatic symptoms. While the atopic constitution may not in itself be associated with heightened responsiveness to bronchial challenge (Woolcock et al, 1978), there is some evidence that hyperreactivity is demonstrable once rhinitis has developed (Stevens et $a l, 1978)$. Both the girls had histories of rhinitis, and the bronchial reactivity to histamine in the elder showed a small increase in association with an attack of hay fever.

Beach and associates (1969) described the pulmonary effects of chlorine in seven chemical workers who were accidentally exposed to high concentrations of chlorine gas. The patients developed acute cough, dyspnoea, and chest pains that subsided over the ensuing week. They were noted to be hypoxic and had evidence of pulmonary oedema, but no studies to detect bronchoconstriction were described in the acute stage of the illness; subsequently one of five subjects examined had evidence of airways obstruction. It was suggested that chlorine may act by causing widespread oedema of the respiratory mucosa. The pathological changes in the airways of these children are therefore likely to be those of degeneration and desquamation of the bronchial epithelium, resulting in exposure of vagal receptors and consequently enhanced vagal activity with bronchial hyperreactivity (Benson, 1975).

Probably the subjects were especially vulnerable because of their atopic background, and it is pertinent that for many known asthmatic patients swimming is a form of exercise that is recommended above others because of a possibly lesser tendency to cause exerciseinduced symptoms. Possibly many asthmatic subjects have experienced effects from bathing in chlorinated water, and the symptom of "coughing water" might be sought when interviewing these patients.

We thank Dr C M Hesling and Dr D Macauley for allowing us to study these children.

\section{References}

Beach, F X M, Jones, E S, and Scarrow, G D (1969). Respiratory effects of chlorine gas. British Journal of Industrial Medicine, 26, 231-236.

Benson, M K (1975). Bronchial hyperreactivity. British Journal of Diseases of the Chest, 69, 227-239.

Hamilton, A, and Hardy, H L (1974). Industrial Toxicology, 3rd edn, pp 215-216. Publishing Sciences Group, Acton, Mass.

Stevens, W J, Lins, R L, and Vermeire, P A (1978). Comparative study of bronchial reactivity and atopic status in asthma and rhinitis. Thorax, 33, 533-543.

Woolcock, A J, Colman, $\mathbf{M} \mathbf{H}$, and Jones, $\mathbf{M} \mathbf{W}$ (1978). Atopy and bronchial reactivity in Australian and Melanesian populations. Clinical Allergy, 8,

Requests for reprints to: Dr C P Mustchin, Chest Clinic, Wythenshawe Hospital, Southmoor Road, Manchester M23 9LT. 